\title{
The Identity Economics of Female Genital Mutilation
}

\author{
Christopher J. Coyne and Rachel L. Coyne*
}

\begin{abstract}
Female genital mutilation (FGM) involves the partial or complete excision of external female genitalia and other damage to the female genital organs. This paper develops the identity economics of FGM as a complement to the agency-cost explanation provided by previous rational choice theorists. We analyze how identity influences the costs and benefits associated with participation in FGM, offering insight into the persistence of the practice, as well as what changing the practice entails. Our analysis also explains some of the counterintuitive phenomena associated with FGM, such as older circumcised females being the main gatekeepers who perpetuate the practice.
\end{abstract}

JEL Codes: B52, D70, Z13

Keywords: capabilities approach, female genital mutilation, identity economics

\footnotetext{
* Christopher J. Coyne (ccoyne3@gmu.edu), Department of Economics, George Mason University, MSN3G4, Fairfax, VA 22030 and Rachel L. Coyne, Senior Fellow, F.A. Hayek Program in Advanced Study in Philosophy, Politics, and Economics at the Mercatus Center at George Mason University. Earlier versions of this paper were presented at the Southern Economic Association Conference in San Antonio, TX, November 2009, and in the Department of Economics seminar at George Mason University, January 2010. We would like to thank an anonymous referee for useful comments and suggestions for improvement.
} 
"Every year, three million girls and women are subjected to genital mutilation/cutting, a dangerous and potentially life-threatening procedure that causes unspeakable pain and suffering." (UNICEF 2005a: vii)

\section{Introduction}

Female genital mutilation (hereafter FGM) involves the partial or complete excision of external female genitalia (primarily the clitoris and labia majora and minora) and other damage to the female genital organs. ${ }^{1}$ The practice of FGM is one of the most significant health and human rights issues in the world today (UNICEF 2005a, World Health Organization 2008, 2011). FGM is typically classified into four categories:

(1) clitoridectomy — partial or complete removal of the clitoris and/or prepuce,

(2) excision - partial or complete removal of both the clitoris and the labia minora, sometimes including removal of the labia majora,

(3) infibulation - decreasing the size of the vaginal opening by cutting the labia minora and/or the labia majora and resealing the cut regions to create a seal over a portion of the vaginal opening, sometimes including removal of the clitoris, and

(4) all other injury to female genitals not justifiable for medical reasons, such as pricking, piercing, scraping, etc. (World Health Organization 2008: 4, 2011).

Most cases of FGM are Type 1, 2, or 4; only 10\% are Type 3 (Yoder and Kahn 2007).

FGM's global prevalence is significant, with an estimated 130 million living women who have undergone the procedure (UNICEF 2005a: 1). The practice is found most often in Africa (especially the western, eastern, and north-eastern regions) as well as in some countries in Asia and the Middle East. ${ }^{2}$ The practice of FGM also takes place among some immigrant populations in Europe and North America. Among countries where FGM is practiced, the rate of prevalence varies widely, from less than $1 \%$ to near $100 \%$. The age at which FGM is performed also varies but is generally between age 0 and 15 , though some adult females also undergo the practice 
(World Health Organization 2008: 4). FGM is performed, on average, when girls are 7 years old (Merck 2005).

A large majority of the existing literature on FGM employs anthropological analysis (see Gruenbaum 2001), including a large number of detailed studies based on fieldwork and interviews (see, for example, Abdalla 1982; Lightfoot-Klein 1989a, 1989b; Isa, Shuib and Othman 1999; Yount 2004; Hernlund and Shell-Duncan 2007; Jirovsky 2010). Existing research also reviews and analyzes initiatives and efforts to change or end FGM practices (see Dorkenoo 1994; Mgbako et al. 2011) and discusses FGM in connection with human rights (Kalev 2004; Nnamuchi 2012) and issues of reproductive health (DeJong 2006; Adam et al. 2010; Browing, Allsworth, and Wall 2010). International development, health, and human rights scholars, practitioners, and organizations have written studies on the practice of FGM in a variety of contexts, emphasizing its risks as well as the need for change while remaining culturally sensitive (see UNICEF 2005a, 2005b; World Health Organization 2008, 2010, 2011; Davis 2010; Fahmy, El-Mouelhy, and Ragab 2010). Additionally, a smaller literature applies rational choice methods to FGM and focuses on the practice as a means of sexual monitoring and control (Posner 1994, Mackie 1996, Chesnokova and Vaithianathan 2010, Wagner 2011).

This paper contributes to this existing literature by developing the identity economics of FGM. Existing rational choice models have yet to include the role of identity despite the fact that it has been identified as an important aspect of FGM. For example, Althaus (1997:130) notes that "Despite these grave risks [of the FGM practice], its practitioners look on it as an integral part of their cultural and ethnic identity, and some perceive it as a religious obligation." Similarly, Gruenbaum (2001: 102) indicates that "Female circumcision practices are deeply entwined with ethnic identity wherever they are found. Understanding this should provide an important insight 
into the tenacity of the practice and people's resistance to change efforts..." Finally, Fuambai Ahmadu, a native Kenyan who underwent the FGM procedure at a young age, indicates that FGM “...is an important source of my social identity. It's what links me with my mother, my grandmothers, my aunts, my female ancestors. It celebrates our history, our connection" (quoted in Goldberg 2009: 46). As these writers indicate, a key function of FGM is establishing and strengthening individual and group identity. The importance of identity for the persistence of FGM is empirically confirmed by Wagner (2011) in a cross-section study of 13 African countries. Her analysis indicates that ethnic identity is the most important determinant of the continuation of FGM. Taken together, these examples and evidence imply that incorporating identity into the rational choice analysis of FGM is crucial to a complete understanding of the practice.

Identity refers to one's notion of self, which influences behavior on two key margins (Akerlof and Kranton 2000: 717). First, the way people perceive themselves influences how they act, resulting in individual identity-based payoffs. Second, the actions of an individual create group identity-based payoffs which affect others. In other words, there is an externality aspect of individual behavior on identity, as that behavior can strengthen or threaten the identity of broader groups.

In developing our identity explanation of FGM, we explain how identity influences the costs and benefits associated with participating in the FGM practice. While anthropologists have noted the connection between identity and FGM, we are the first to explore how identity influences the costs and benefits associated with participating, or refusing to participate, in the practice. In doing so, we also offer insight into why the practice persists and what is required for it to change. Finally, our analysis explains some of the counterintuitive phenomena associated 
with FGM. For example, our analysis explains why older females who have undergone the FGM procedure are often the main "gatekeepers" of the practice, despite the fact that they are in the best position to realize the pain and health issues associated with the practice.

We proceed as follows. Section 2 discusses why the standard rational choice, agency-cost explanation for FGM, which focuses on the monitoring costs associated with the sexual behavior of females, is incomplete. Section 3 develops the identity economics of FGM as a complement to the agency-cost explanation and interprets the main implications of the model. Section 4 explores the predictions of the model and the evidence related to those conjectures. Section 5 concludes with the implications of our analysis.

\section{The Incompleteness of the Agency-Cost Explanation}

The standard rational choice explanation for FGM focuses on agency costs, noting that it is costly for males - the principals - to monitor the sexual activity of females - the agents. The rational choice literature highlights males as principals in several different contexts.

Posner (1994) identifies the practice of FGM as a mechanism for lowering agency costs by husbands over their wives in polygamous marriages, or on the part of fathers over their daughters. He writes that, "A polygamist, or for that matter the father of a girl, might tumble to the idea that a wife whose clitoris was removed would require less supervision by her husband. Such women would become more valuable in the marriage market..." (1994: 214). In the case of polygamy, husbands must have a means of ensuring that their wives remain faithful. In the case of parents, the father wants to ensure that his daughters remain virgins in order to increase their value on the marriage market. In both instances, in the face of imperfect information, FGM can be seen as a means of reducing monitoring costs. Along these lines, Posner (1994: 257) notes 
that FGM is " ....analogous to a medieval chastity belt, a measure for preventing the wife from committing adultery when...the husband would face insuperable costs of maintaining surveillance over her by normal methods."

Mackie (1996) begins his analysis with the socio-biological assumption that people desire to raise their own children. Given this, he notes that males face a problem of paternal certaintyi.e., whether or not their wife's children are in fact their own. In this context FGM lowers the cost of monitoring sexual behavior by ensuring virginity at the time of marriage and by removing sexual pleasure which reduces the likelihood of females cheating after marriage. Along these lines Mackie (1996: 1004) writes that FGM "prepares for marriage, is a prerequisite for marriage, makes for better marriage prospects, makes possible the security available through marriage, and so on." Relying on this logic, Chesnokova and Vaithianathan (2010) develop a model of FGM as a pre-marital investment which allows women to marry at an earlier age and attract wealthier partners.

If these agency-cost explanations are accurate, then we should see the maintenance of virginity and, directly related, the marriage prospects of females as the main explanatory factors behind the persistence of FGM. However, the available data indicates that these factors, while relevant, are not the dominant drivers of the persistence of FGM. The most comprehensive data on FGM comes from the Demographic and Health Surveys which are collected by Measure DHS+ and funded by the U.S. Agency for International Development (USAID). Yoder et al. (2004) provide a comparative analysis of the DHS reports related to FGM, providing insight into the reasons for the persistence of FGM.

Among the questions asked of females in the DHS surveys was whether they believed FGM should continue or cease in the future. Among those that responded that they wanted the 
practice to continue, the surveys then asked the reason why the respondent supported the continuance of FGM. Table 1 shows the responses with the six categories offered to respondents. Respondents were given the opportunity to select multiple reasons for continuing the practice.

Table 1: Reasons to Continue the FGM Practice $(\%)^{3}$

\begin{tabular}{lcccccc}
\hline $\begin{array}{c}\text { Survey country } \\
\text { (year of survey) }\end{array}$ & $\begin{array}{c}\text { Custom/ } \\
\text { tradition }\end{array}$ & $\begin{array}{c}\text { Good } \\
\text { tradition }\end{array}$ & Virginity & Religion & $\begin{array}{c}\text { Hygiene/ } \\
\text { cleanliness }\end{array}$ & $\begin{array}{c}\text { Marriage } \\
\text { prospects }\end{array}$ \\
\hline Egypt 1995 & NA & 58 & 9 & 31 & 36 & 9 \\
Eritrea 1995 & 69 & 53 & 15 & 12 & 15 & 4 \\
Sudan (northern) 1989- & 68 & 19 & 7 & 14 & 8 & 5 \\
1990 & & & & & & \\
Mali 1995-1996 & 61 & 28 & 5 & 13 & 6 & 3 \\
Burkina Faso 1998-1999 & 71 & NA & 10 & 9 & 10 & 4 \\
Niger 1998 & 22 & NA & 27 & 6 & 2 & 29 \\
Côte d'Ivoire 1998-1999 & 68 & NA & 15 & 11 & 17 & 36 \\
Central African Republic & 70 & 26 & 13 & $<1$ & 1 & 9 \\
1994-1995 & & & & & & \\
Nigeria 1999 & 50 & 35 & 14 & 2 & 5 & 7 \\
Kenya 1998 & 56 & 42 & 30 & 5 & 4 & 18 \\
Yemen 1997 & 36 & 12 & 6 & 33 & 46 & 3 \\
\hline
\end{tabular}

In order to make clear what this table is showing, consider the case of Egypt, where $82 \%$ of respondents indicated that they supported the continuation of the FGM practice going forward. Of those respondents, 58\% cited "good tradition" for the reason why, while $9 \%$ cited "virginity" and "marriage prospects." Beyond Egypt, the available data indicate that "virginity" and "marriage prospects" are not the main factors behind the desire of females to continue the practice of FGM. This implies that other factors, such as tradition and identity, are relevant and need to be incorporated into rational choice analysis.

Next, consider the case of FGM as a solution in polygamous marriages and male absenteeism as suggested by Posner (1994). There is some empirical evidence to support this 
explanation for FGM. For example, in one empirical study of FGM in northeastern Africa, Hicks (1993: 162) found a correlation between the practice of FGM and male absenteeism. However male absenteeism, by itself, as an explanation for FGM is incomplete. Consider Table 2, which shows the prevalence rates of FGM along with the polygamy rates for a select group of countries based on the availability of data.

Table 2: FGM Prevalence and Polygamy Rates ${ }^{4}$

\begin{tabular}{lcc}
\hline \multicolumn{1}{c}{ Region/Country } & $\begin{array}{c}\text { FGM } \\
\text { Prevalence (\%) }\end{array}$ & $\begin{array}{c}\text { \% married men in a } \\
\text { polygamous union }\end{array}$ \\
\hline Northeastern Africa & & \\
Egypt & 97 & $<10$ \\
Sudan & 90 & 16 \\
Ethiopia & 80 & $<10$ \\
Northern West Africa & & \\
Guinea & 99 & 37 \\
Mali & 92 & 29 \\
Burkina Faso & 72 & 40 \\
Niger & 5 & 15 \\
& & \\
Southern West Africa/ & & \\
Middle Africa & & 20 \\
Côte d'Ivoire & 45 & 13 \\
Central African Republic & 43 & 19 \\
Nigeria & 25 & 31 \\
Benin & 17 & \\
& & 13 \\
Eastern Africa & & 16 \\
Kenya & 38 & $<10$ \\
Tanzania & 18 & \\
Western Asia & & \\
Yemen & 23 & \\
\hline
\end{tabular}


As Table 2 indicates, there is not a clear correlation between the prevalence of FGM and polygamy rates across all countries. In several societies-e.g., Egypt, Sudan, Ethiopia, Guinea, Mali - with relatively high FGM prevalence rates, there are relatively low rates of married men in polygamous unions.

Note that in both cases the data presented does not disqualify the agency-cost explanation for FGM. It does, however, imply that it is an incomplete explanation and suggests that there are additional factors, such as identity, behind the FGM practice. Even those who subscribe to the agency-cost explanation recognize the importance of other factors, such as identity, for understanding FGM. For example, Mackie (1996: 1004) notes that "One common explanation [for FGM], sometimes neglected...is simply that "such is the custom or tradition here"" or that “"this $[\mathrm{FGM}]$ is a practice that distinguishes us from our neighbors'." He goes on to note further that the FGM practice also "functions to promote solidarity of the group" (1996: 1004). This implies that identity plays an important role in understanding FGM in addition to the standard agency-cost explanation for the practice.

Indeed, evidence indicates that one of functions of FGM is to strengthen individual and group identity. Gruenbaum (2001: 103) notes that body alteration, of which FGM is one type, is often "... a part of rituals of transition that recognize a new status... and initiate the formation of a new identity..." She goes on to note that FGM “...continues to serve as such a marker of ethnic, and in some cases class, identity" (Gruenbaum 2001: 104). Matias (1996), likewise, notes that FGM is an important identity marker which serves as a symbol to differentiate insiders from outsiders. Finally, Williams (1998: 33) emphasizes that the practice of FGM involves a complex array of "...deeply held beliefs and values which place it at the core of...identity." Taken together, this implies that FGM plays a central role in individual and group identity. Given this, 
it is crucial to provide a rational choice analysis for how identity influences decisions regarding participation in FGM. Combined with the agency-cost explanation of FGM, the identity economics of FGM provides a more complete rational choice understanding of the practice.

\section{The Identity Economics of FGM}

The economics of identity, developed by Akerlof and Kranton (2000, 2010), can be applied to FGM to provide insight into the role that identity plays in this practice. At the core of the model is the assumption that identity is grounded in social categories existing in a specific context. Where the practice of FGM exists, relevant categories may include being a good parent, being an adult versus a child — i.e., coming-of-age — being a suitable marriage partner, or being a member of a religious organization or a certain peer group. An important aspect of utility comes from identity, which is a function of an individual's social category, as well as the extent to which there is a match between an individual's characteristics and the prescription-i.e., acceptable behaviors - of the social category. Also important is whether the actions of others in the peer group align with the prescription of the social category. This implies that people derive satisfaction from their own behavior as well as from the emergence and strengthening of an identity that fulfills the prescription associated with a specific social category.

To provide a concrete example, consider the social category of "good parent" in a society where FGM is widely accepted. This is a common situation, as indicated by Yoder et al. (2004: 43) who note that "among the women who think FGM/C [Female Genital Mutilation/Cutting] should continue, half to two-thirds regard FGM/C as part of their commonsense understanding of what parents should do for their daughters - that they are doing what they think is appropriate." In such a context, parents derive utility from ensuring that their daughters participate in FGM on 
two margins. First, they increase their daughter's prospects on the marriage market. Holding all else constant, knowing that their daughters have more as compared to fewer marriage options will increase parents' utility. Second, parents also derive utility from strengthening their identity as "good parents" in the eyes of others in the broader community who are also part of the same social category.

A key aspect of the identity model is the spillover effect of individual behavior on the broader social group. The actions of one person affect the identity of others. For example, the identity of "good parents"-where the prescription is ensuring that daughters participate in FGM — may be threatened by a child who resists participation.

Similar logic also helps to explain why the practice of FGM persists even in the presence of health risks and why young females often indicate that they look forward to participating in FGM despite the associated pain (Abdallah 1982: 51; Dorkenoo 1994: 46, 161). To understand why, consider the social category of "adult" in a society where the practice of FGM is well established. FGM is often viewed as an important coming-of-age ritual, signaling the transition from childhood to adulthood. In such cases, FGM is rewarded by the existing group of adultsconsisting of those who have already participated in FGM. Females, or the parents of females, who resist participation in FGM threaten the identity of other members in the adult group. The result is that part of the prescription of being in the adult category is to punish those refusing to participate in the practice in order to protect the identity of the group. This punishment often takes the form of ostracism or harassment of varying degrees (World Health Organization. 2008: 5). In some cases the number of marriage prospects available to females refusing to participate in FGM is significantly diminished. In other cases the family of the daughter refusing to participate is shamed by the community. At the extreme, refusal to participate in FGM is met with physical 
violence and expulsion from the community. The fear of punishment by the broader social group for refusing to participate is an important motivating factor for girls to take part in the FGM practice.

The FGM Identity Game is shown in Figure 1 and clarifies the dynamics of identity described above. It also illuminates the conditions under which practices linked with identity persist or change.

\section{Figure 1: The FGM Identity Game}

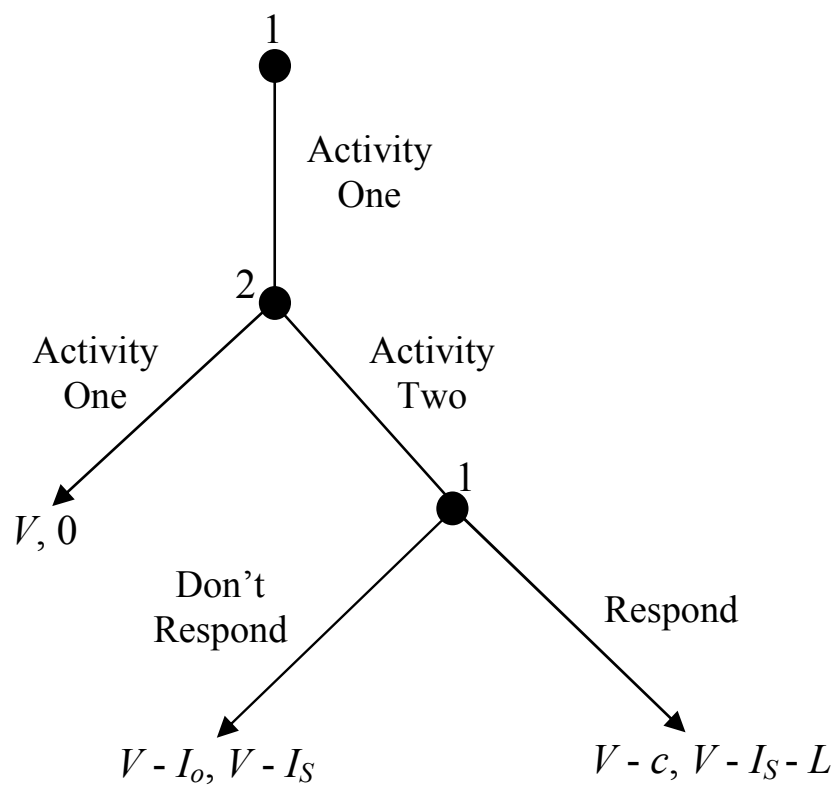

Figure Key:

Player 1: The 'adult' (any member of the 'adult' social category)

Player 2: The young female or the parents of the young female

Activity 1: Participation in the FGM ritual

Activity 2: Refraining from participation in the FGM ritual 
There are two players and two "Activities"-Activity 1 and Activity 2. In the context of our analysis, Activity 1 should be understood as participation in FGM, while Activity 2 is refraining from participation. A player receives a payoff of $V$ when she chooses her preferred activity and a payoff of 0 otherwise. For simplicity, consider two social categories-"FGM proponent" or "FGM opponent" - and assume that all people are initially thought of by others as being a FGM proponent. Further, assume that the behavioral prescription for an "FGM proponent" is Activity 1 while the prescription for an "FGM opponent" is Activity 2. If a player chooses Activity 2, they are not considered to be a proper and true "FGM proponent." The result will be a loss of the player's "FGM proponent" identity and, hence, a reduction in utility by $I_{s}$, where $s$ refers to "self." This coincides with the case where a female or her parents refuse(s) to participate in FGM and is therefore punished through harassment or ostracism.

In order to capture the spillover effects on identity, the model assumes that a player who chooses an activity that runs counter to the prescribed social category also negatively impacts the other player through a loss of identity. Recall that the refusal of a female or her parents to participate in FGM threatens the identity of the broader 'adult' social category. This loss to the other player is represented by $I_{o}$, where " $o$ " refers to "other."

As illustrated in Figure 1, Player 1-i.e., the "adult," which refers to any member of the existing adult social category—chooses first. In a subgame perfect equilibrium, Player 1, as a true "FGM proponent," would always choose Activity 1, hence the absence of Activity 2 as an initial option. However, Player 2-i.e., the young female or the parents of the young femalemay choose Activity 1 or Activity 2 depending on the respective payoffs. Assume that Player 2, although perceived as an "FGM proponent" by others, actually prefers Activity 2 because they are, in reality, an "FGM opponent." An example would be a case where the community perceives 
that a young female is going to participate in FGM, but the young female or her parents do(es) not actually want to take part and resist(s).

Following the selection of Activity 2 by Player 2, Player 1 has two options. The first involves "responding" to Player 2's selection of Activity 2. The potential benefit of "responding" is that Player 1 restores their identity at a cost of $c$ while imposing a loss on Player 2 equal to $L$. In the context of our analysis, this would correspond to a member of the 'adult' group punishing a female who is resisting participation in FGM. The punishment imposes a cost on the reluctant female while strengthening the punisher's identity as a true adult and FGM proponent. If Player 1 chooses "Don't Respond," they suffer a loss of $I_{o}$ while Player 2 suffers a loss of $I_{s}$.

There are four possible Nash equilibria to the game depending on the values of the relevant variables (Akerlof and Kranton 2000: 730). We interpret these equilibria in the context of our analysis to shed light on the dynamics of identity as they relate to FGM. The Nash equilibria are:

(1) Player 1 plays "Respond" and deters Player 2 from resisting FGM when $c<I_{o}$ and $I_{S}$ $<V<I_{S}+L$. This will be the equilibrium outcome when the loss of identity to Player 1 from Player 2 undermining the practice of FGM is relatively high and when the loss of identity to Player 2, as well as the punishment imposed by Player 1, is relatively high. This equilibrium describes those situations where FGM persists because of fear of severe responses such as significant losses of family honor, violent harassment, and extreme forms of ostracism.

(2) Player 1 chooses to "Respond" against Player 2's decision to engage in Activity 2, but this response fails to deter Player 2 from effectively resisting participation in FGM, when $c<I_{o}$ and $I_{s}+L<V$. This equilibrium indicates that movement away from FGM is possible, but high cost. The shift away from FGM will occur only when Player 2's utility from refraining from participating in FGM is relatively high when compared to the associated cost.

(3) Player 2 chooses Activity 2 (i.e., refraining from participation in FGM) and Player 1 does not respond, when $c>I_{o}$ and $I_{S}<V$. This equilibrium represents a situation 
where the movement away from FGM is most likely. It is important to note though that this outcome still has a positive cost whenever $I_{s}>0$.

(4) Player 2 chooses Activity 1 no matter how Player 1 may respond if Activity 2 were chosen instead, when $I_{s}>V$. Under this scenario, refusing to participate in FGM leads to a significant reduction in utility for Player 2 due to the loss of identity. In this case the potential response from Player 1 does not even factor into Player 2's decision. Under this scenario, the practice of FGM will continue, since it is deeply intertwined with the identity of community members.

The FGM-identity model captures many important aspects of the practice of FGM. When deciding whether to subject their daughter to the practice of FGM, parents will consider the social context—community expectations, social norms regarding marriage and religion, etc.and the impact of alternative choices on their identity and the identity of their daughter. Likewise, when considering whether to participate in FGM, young females will consider the wishes of their family as well as community expectations. Based on the perceived negative effect on their respective identities, the parents and daughter may rationally decide to participate in FGM even if they are reluctant to do so otherwise. Once this identity decision is made and a young female becomes part of the "adult" group, her optimal behavior is then determined by fulfilling the prescription of the "adult" category. Although we framed the identity game in terms of FGM as a coming-of-age ritual, the same logic can be applied to cases where FGM is associated with purity, commitment to a religion, or other social categories.

\section{Predictions and Evidence}

The model of the identity economics of FGM generates several predictions. Existing evidence supports them.

1. Many females who are subjected to FGM will become supporters of the practice. 
The FGM identity model predicts that once females participate in the FGM practice, they will then have an incentive to defend and perpetuate the practice, since their identity is linked to the practice. Participation in FGM signals the transition to a new social category, the prescription of which includes protecting the FGM practice. Those in the social category will want to defend their identity, which is now defined by participation in FGM, against outside threats, which includes younger generations of females who may refuse to participate in FGM. This implies that females will tend to be proponents of FGM after they participate in the practice, even if they originally resisted FGM or experienced pain and suffering due to participation.

Evidence indicates that in many societies where FGM is practiced "...older women who have themselves been mutilated often become gatekeepers of the practice..." (World Health Organization 2008: 7). The role of gatekeeper involves preparing young girls for FGM, carrying out the practice, and contributing to the punishment of young females who resist participation. Outside of the identity model, this may appear counterintuitive and irrational because females who have experienced the FGM procedure are in the best position to understand the pain and health issues associated with the practice. However, the identity model explains why this gatekeeper phenomenon is a rational response to changes in costs and benefits. Once a female participates in FGM, the costs and benefits they face shift, resulting in an incentive to defend and perpetuate the practice precisely because of the benefits associated with individual and group identity.

Along these lines, a report by the World Health Organization (2008: 7) indicates that women become gatekeepers of FGM because they see "....it as essential to the identity of women and girls." Similarly, Toubia and Sharief (2003: 257, 260) note, "Older women who have experienced the cutting...become the 'gatekeepers' of the culture by incorporating FGM as 
essential to their own identity and ensure that their daughters experience the same social marker and retain the benefits." In both cases the role of gatekeeper can be explained by the benefits associated with identity as it relates to the continuation of FGM.

\section{Sustainable changes to FGM practices require changes to identity.}

The FGM identity model predicts that changes to FGM practices require changes to the costs and benefits associated with a loss of identity—both for the individual and the broader social group - for choosing not to participate in FGM. Specifically, the model indicates that changes to the identity parameters (the $I_{o}$ and $I_{s}$ parameters) or a reduction in the loss $(L)$ imposed by members of the group against those who decide not to participate in FGM are required for change. Decreasing the loss $(L)$ imposed by other members of the community on those who choose not to participate in FGM will lead to fewer people participating in the practice. Likewise, reducing the importance of FGM for a social group's identity will lower the value attached to the $I_{o}$ and $I_{s}$ parameters, resulting in a decrease in FGM.

In societies where FGM is practiced, notions of identity are typically context-specific and vary across local groups as compared to some notion of a uniform national identity. This implies that changes to identity parameters are more likely to take hold when they occur on a smaller scale. Indeed, evidence indicates that cases of successful changes to FGM practices have typically started at the local level. For example, a UNICEF (2005a: 23) report notes that "the most successful [initiatives of change] are participatory in nature and generally guide communities to define problems and solutions themselves." Consider that the prevalence of FGM has fallen in Gambia, Kenya, Tanzania, and Uganda through the local efforts of non-profits and community leaders who are knowledgeable regarding local practices, culture, and 
perceptions of identity. Local efforts are more likely to appreciate the nuances of identity and the perceived threats to identity from outsiders.

Evidence also indicates that marginal changes to existing FGM practices will be more effective, as compared to wholesale changes, because the loss of identity will not be as great. The common characteristic across the aforementioned countries where change has been observed is that reform efforts in these countries did not aim at wholesale change in the coming-of-age ritual, of which FGM was one part. Instead, they emphasized maintaining the socio-cultural aspects of the meta-ritual while making changes to the FGM aspect (UNICEF 2005a: 26). The result was that the identity associated with the meta-ritual remained largely intact although the FGM aspect was changed. In other words, by making marginal changes to the meta-ritual, the losses of identity $-I_{o}$ and $I_{s}$-from altering the FGM aspect were minimal.

\section{Formal laws banning FGM will be ineffective absent changes in identity.}

The FGM identity model predicts that formal laws banning FGM which fail to appreciate the role played by identity will be ineffective. Where the FGM practice has a strong link to identity, participants will tend to ignore the law precisely because the cost of following it in terms of lost identity would be significant.

In recent years there has been an increased effort by many national governments and international organizations to change FGM practices through top-down national laws making FGM a criminal offense. In many cases these laws have failed to dramatically change FGM practices. For example, in 1997, Egypt's highest appeals court, the Court of Cassation, upheld a national ban on the practice of FGM. According to the law, those who failed to follow the ban were subject to criminal punishment. Despite the national law, a 2000 survey by the United 
States Agency for International Development (USAID 2000) found that 97\% of Egypt's population still engaged in the practice. More broadly, a study of national FGM laws found that of the twenty-eight countries in Africa and the Middle East where FGM is practiced, the laws had been utilized in only four countries, and with a minimal impact (Rahman and Toubia 2000).

One reason for the failure of national laws banning FGM is that members of social groups practicing FGM tend to view these efforts as threats to their identity. Indeed, interviews and surveys indicate that women in societies where FGM is practiced and accepted are largely critical of attempts at exogenous change by those viewed as outsiders (Dorkenoo 1994). Keeping in mind that identity is often defined at the local level in societies where FGM is practiced, outsiders include not only foreigners, but also members of the national government and others who are not considered to be part of the local culture. In terms of the identity model, members of the "adult" social group view those outside the group-including law enforcement-as threatening their identity by trying to curtail FGM and therefore resist change. This leads to a rejection of the formal, national law. Along these lines, a Regional Commissioner in Ghana noted that formal laws banning FGM were ineffective because "[t]he obstacles are basically the entrenched belief system of the communities. They argue that our forefathers did the same thing and gave birth to us. How can you say it is wrong and why should we be the ones to stop that age-old practice? And they see it as a distinguishing feature of themselves" (quoted in Ako and Akweongo 2009: 51). This again highlights the importance of identity in the persistence of FGM, even when formal laws banning the practice are passed.

A related reason for the ineffectiveness of formal laws is the prohibitive enforcement costs absent changes in identity as noted in the previous prediction. Without changes in the underlying identity, members of communities where FGM exists will tend to ignore formal laws, 
and the practice will continue. In such instances, enforcing the law would involve arresting and imprisoning entire communities. The problem again is that formal laws, by themselves, do not necessarily impact the identity parameters in a manner resulting in permanent changes in FGM practices. To understand the strength of identity and social conventions, even in the presence of formal laws to the contrary, consider the case of immigrants from FGM-practicing societies who migrate to countries where FGM is largely absent. In some cases immigrants continue the practice even though formal laws make FGM illegal (UNICEF 2005a: 27; Kool 2010). These occurrences provide perhaps the strongest evidence of the identify effect, as other associated benefits associated with FGM are diminished-e.g., the marriage market is larger, etc. Further, this highlights that role of internal, self-imposed and self-enforcing norms that contribute to the persistence of FGM. This indicates that changing the practice of FGM is a matter of altering fundamental beliefs and notions of identity, not simply formal laws.

There is evidence that formal laws making FGM illegal can be effective when they support existing opposition to the practice at the local level (see UNICEF 2005a: 29; Hernlund and Shell-Duncan 2007: 47-8). This highlights that formal laws will have a reinforcement effect when they codify underlying practices and beliefs. Where formal rules regarding FGM align with informal practices, social groups will not view their identity as being threatened. However, where there is a disconnect between formal FGM laws and informal practices, the former will be ineffective, while the latter will tend to persist.

\section{Conclusion}

Our analysis has several implications for our understanding of the practice of FGM. First, FGM is a rational practice. The variety of participants involved in the FGM practice-children, 
parents, practitioners, community members, etc.- - weigh the costs and benefits associated with participating in the practice. Recognizing FGM as a rational practice is critical for understanding not only why the practice exists but also how it changes. The view of FGM as an irrational practice "...suggests that practitioners are somehow less rational than people in 'modern' societies and justifies a heavy-handed approach that strives to teach...people who are seen as 'ignorant"' (Gruenbaum 2001: 16-17). As noted, this heavy-handed approach by those considered to be outsiders is likely to be unsuccessful because it fails to appreciate the identity underlying the FGM practice. Formal laws banning FGM at the national level may be useful in gaining political favor internationally with governments and groups calling for improved human rights, but they will do little to stop the actual practice absent changes to identity as perceived by the citizens themselves. This is because the enforcement costs of formal laws will be significantly high where the belief systems of citizens deviate from the dictates of the formal rules prohibiting FGM.

Second, a central function of FGM is to establish and perpetuate individual and group identity. The decision of people to engage, or to refrain from engaging, in the practice of FGM affects not only the identity of the decision maker, but also the broader social group. The identity explanation for FGM, which has been neglected by rational choice theorists to date, complements the common agency-cost explanation for the practice. FGM can serve to reduce the costs of monitoring the sexual behaviors of females, but evidence also indicates that it is entwined with identity. The identity approach to FGM indicates that efforts to alter or curtail the FGM practice must recognize the cost of lost identity as a crucial parameter.

Finally, even in the face of persistence due to identity, the practice of FGM can change. Change ultimately requires shifts in belief systems regarding the link between identity and the 
practice of FGM. Changes to belief systems are required to alter the costs and benefits associated with the identity that fulfills the prescription associated with relevant social groups. Specifically, decreases in the prevalence of FGM require a reduction in perceived benefits to identity from participating in FGM. In terms of policy, the main implication is that a shift in focus away from simple top-down prescriptive policies and toward collective action approaches at the local level is typically necessary to promote successful change in FGM practices. This includes, but is not limited to, exposure to alternative belief systems through interactions with non-profit organizations or through economic and social interactions. 


\section{References}

Abdalla, Raqiya Haji Dualeh (1982) Sisters in Affliction: Circumcision and Infibulation of Women in Africa, London: Zed Press.

Adam, Taghreed, Heli Bathija, David Bishai, Yung-Ting Bonnenfant, Manal Darwish, Dale Huntington, and Elise Johansen (2010) Estimating the obstetric costs of female genital mutilation in six African countries, Bulletin of the World Health Organization, Vol. 88, No. 4, pp. 281-288.

Akerlof, George A. and Rachel Kranton (2000) Economics and Identity, Quarterly Journal of Economics, Vol. 105, No. 3, pp. 715-753.

.2010. Identity Economics: How Our Identities Shape Our Work, Wages, and Well-Being, New Jersey: Princeton University Press.

Ako, Matilda Aberese and Patricia Akweongo (2009) The Limited Effectiveness of Legislation Against Female Genital Mutilation and the Role of Community Beliefs in Upper East Region, Ghana, Reproductive Health Matters, Vol. 17, No. 34, pp. 47-54.

Althaus, Frances A. (1997) Female circumcision: Rite of passage or violation of rights? International Family Planning Perspectives, Vol. 23, No. 3, pp. 130-133.

Browing, Andrew, Jennifer E. Allsworth and L. Lewis Wall (2010) The Relationship Between Female Genital Cutting and Obstetric Fistulae, Obstetrics and Gynecology, Vol 15, No. 10, pp. 578-582.

Chesnokova, Tatyana and Rhema Vaithianathan (2010) The Economics of Female Genital Cutting, The B.E. Journal of Economic Analysis \& Policy, Vol. 10, No. 1, Article 64.

Davis, Dena S. (2010) Ritual Genital Cutting of Female Minors, Pediatrics Vol. 125, No. 1, pp. 1088-1093.

DeJong, Jocelyn (2006) Capabilities, Reproductive Health and Well-Being, Journal of Development Studies, Vol. 42, No. 7, pp. 1158-1179.

Dorkenoo, Efua (1994) Cutting the Rose. Female Genital Mutilation: The Practice and its Prevention, London: Minority Rights Group.

Fahmy, Amel, Mawaheb T. El-Mouelhy and Ahmed R. Ragab (2010) Female Genital Mutilation/Cutting and Issues of Sexuality in Egypt, Reproductive Health Matters, Vol. 18, No. 36, pp. 181-190.

Goldberg, Michelle (2009) Rights versus Rites, The American Prospect, Vol. 20, No. 4, pp. 4650. 
Gruenbaum, Ellen (2001), The Female Circumcision Controversy: An Anthropological Perspective, Pennsylvania: University of Pennsylvania Press.

Hernlund, Ylva and Bettina Shell-Duncan (2007) Contingency, Context and Change: Negotiating Female Genital Cutting in The Gambia and Senegal, Africa Today, Vol. 53, No. 4, pp. 43-57.

Hicks, Esther K. (1993) Infibulation: Female Genital Mutilation in Islamic Northeastern Africa, New Jersey: Transaction.

Isa, Ab. Rahman, Rashidah Shuib and M. Shukri Othman (1999) The Practice of Female Circumcision among Muslims in Kelantan, Malaysia, Reproductive Health Matters, Vol. 7, No. 13, pp. 137-144.

Jirovsky, Elena (2010) Views of Women and Men in Bobo-Dioulasso, Burkina Faso, on Three Forms of Female Genital Mutilation, Reproductive Health Matters, Vol. 18, No. 35, pp. 84-93.

Kalev, Henriette Dahan (2004) Cultural Rights or Human Rights: The Case of Female Genital Mutilation, Sex Roles, Vol. 51, No. 5/6, pp. 339-348.

Kool, Renee (2010) The Dutch Approach to Female Genital Mutilation in View of the ECHR: The Time for Change Has Come, Utrecht Law Review, Vol. 6, No. 1, pp. 51-61.

Lightfoot-Klein, Hanny (1989a) Prisoner's of Ritual: An Odyssey into Female Genital Circumcision in Africa, New York: The Haworth Press.

(1989b) The Sexual Experience and Marital Adjustment of Genitally Circumcised and Infibulated Females in The Sudan, The Journal of Sex Research, Vol. 26, No. 3, pp. 375392.

Mackie, Gerry (1996), Ending Footbinding and Infibulation: A Convention Account, American Sociological Review, Vol. 61, No. 6, pp. 999-1017.

Matias, Aisha Samad (1996) Female Circumcision in Africa, Africa Update III, Available online: http://www.h-net.org/ africa/sources/clitorodectomy.html

Merck (2005) Female Genital Mutilation, The Merck Manuals: Online Medical Library. Available online: http://www.merck.com/mmpe/sec19/ch301/ch301b.html

Mgbako, Chi, Meghna Saxena, Anna Cave, Helen Shin, Nasim Farjad (2010) Penetrating the Silence in Sierra Leone: A Blueprint for the Eradication of Female Genital Mutilation, Harvard Human Rights Journal, Vol 23, pp. 111-140.

Nnamuchi, Obiajulu (2012) “Circumcision" or "Mutilation”? Voluntary or Forced Excision? 
Extricating the Ethical and Legal Issues in Female Genital Ritual, Journal of Law and Health Vol. 25, No. 1, pp. 85-121.

Posner, Richard A. (1994) Sex and Reason, Massachusetts: Harvard University Press.

Rahman, Anika and Nahid Toubia (2000) Female Genital Mutilation: A Guide to Laws and Policies Worldwide, London: Zed Books.

Tertilt, Michèle (2005) Polygyny, Fertility, and Savings, Journal of Political Economy, Vol. 113, No. 6, pp. 1341-1371.

Toubia, Nahid F.and E.H. Sharief (2003) Female Genital Mutilation: Have we Made any Progress? International Journal of Gynecology \& Obstetrics, Vol. 82, No. 3, pp. 251-261.

UNICEF (2005a) Changing a Harmful Social Convention: Female Genital Mutilation/Cutting, Italy: UNICEF.

(2005b) Female Genital Mutilation/Female Genital Cutting: A Statistical Exploration, New York: UNICEF.

United States Agency for International Development (USAID) (2000) Egypt Demographic and Health Survey, Available online: http://www.measuredhs.com/topics/gender/FGCCD/eg.cfm

Wagner, Natashcha (2011) Why Female Genital Cutting Persists, Mimeo.

Williams, Linda A. (1998) Eradicating Female Circumcision: Human Rights and Cultural Values, Health Care Analysis, Vol 6, No. 1, pp. 33-35.

World Health Organization (2008) Eliminating Female Genital Mutilation - An interagency Statement, World Health Organization.

(2010) Female genital mutilation. Fact Sheet No. 241, http://www.who.int/mediacentre/factsheets/fs241/en/

(2011) Female genital mutilation and other harmful practices, http://www.who.int/reproductivehealth/topics/fgm/prevalence/en/index.html

Yoder, P. Stanley, Noureddine Abderrahim and Arlinda Zhuzhuni (2004) Female Genital Cutting in the Demographic and Health Surveys: A Critical and Comparative Analysis. DHS Comparative Report No. 7, Maryland: ORC Macro.

Yoder, P. Stanley and Shane Khan (2007) Numbers of women circumcised in Africa: The production of a total, Calverton, Macro International Inc.

Yount, Kathryn M. (2004) Symbolic Gender Politics, Religious Group Identity, and the Decline 
in Female Genital Cutting in Minya, Egypt, Social Forces, Vol. 82, No. 3, pp. 1063-1090.

${ }^{1}$ We use "female genital mutilation" in the broadest sense to include female genital cutting and female circumcision.

${ }^{2}$ The specific origins of FGM are unknown. As Gruenbaum (2001: 42) notes, "The difficulty of offering a causal explanation for female circumcision practices is further complicated by its antiquity."

${ }^{3}$ Source: Yoder et al. (2004: 42).

${ }^{4}$ Source of FGM Prevalence data is Yoder et al. (2004: 26) and source of polygamy data is Tertilt (2005: 1367). 